\title{
Das Vorkommen von Erepsin im Pankreas.
}

\author{
Von
}

H. M. Vernon (Oxford).

(Der Redaktion zugegangen am 29. November 1906.)

Von der Tatsache ausgehend, daß die fibrinlösende Kraft und das peptonzerstörende Vermögen pankreatischer Auszüge voneinander unter gewissen Bedingungen beträchtlich abweichen, bin ich $\mathrm{zu}$ der Überzeugung gekommen, daß solche Auszüge zwei voneinander verschiedene Fermente enthalten, nämlich das Trypsin und das Erepsin. ${ }^{1}$ ) Nach einer mühsamen Untersuchung dieser Fragestellung, hat Herr Dr. Karl Mays ${ }^{2}$ ) meine Befunde insoweit bestätigt, daß er glaubt tryptische und ereptische Eigenschaften des Pankreas unterscheiden zu müssen, doch greift er meine Untersuchungen und Argumentation an. Dieses kann ich nur dadurch erklären, daß er meine Arbeit nicht verstanden oder falsch aufgenommen hat. Es ist $\mathrm{z}$. B. von mir angegeben worden, daß aus drei besonderen Versuchen sich der Schluß ziehen läßt, daß im Durchschnitt ungefähr die Hälfte der peptonzersetzenden Kraft eines gewissen pankreatischen Auszuges durch Trypsin, während die andere Hälfte durch Erepsin bedingt sei; aber Herr Dr. Mays versucht nachzuweisen, daß einige meiner Zahlenangaben verschiedener Versuche mit meiner Hypothese nicht in Einklang stehen, und sagt, daß entweder meine Beobachtungen oder meine Schlüsse irrig sein müßten. Er ignoriert die Tatsache, daß ich selber sorgfältig darauf hingewiesen habe, daß aes unmöglich ist, mit Sicherheit $\mathrm{zu}$ bestimmen, $\mathrm{zu}$ welchem Grade die peptonzersetzende Kraft eines Auszuges vom Trypsin oder vom Erepsin abhängt» (S. 344). Auch teilt er nicht mit, daß ich zuerst ausdrücklich darauf hingewiesen habe, daß die Methode der Peptonhydrolyse es nur zuläßt, «den Gehalt des peptonzersetzenden Fermentes ganz ungefähr (roughly) $\mathrm{zu}$ bestimmen, und daß in bezug auf das peptonzersetzende Ferment von einem wirklich genauen Vergleiche des Fermentgehaltes verschiedener pankreatischer Auszüge kaum die Rede sein kann (S. 340).

In einem anderen Versuche zeigte ich, daß der Auszug eines Katzenpankreas eine mäßige peptonzersetzende Wirkung hatte, während

1) H. M. Vernon, Journal of Physiol., Bd. XXX, S. 330 (1903).

2) Karl Mays, Diese Zeitschrift, Bd. XLIX, S. 124 (1906). 
die fibrinlösende Kraft beinahe ganz und gar abwesend war. Um das Trypsinogen, welche es enthielt, in Trypsin umzuändern, setzte ich $2 \%$ eines Dünndarmauszuges, welcher Entorokinase enthielt, hinzu und, worauf ich besonders hinwies, gleichfalls Erepsin. Trotzdem gewinnt man von der Arbeit des Herrn Dr. Mays den Eindruck, als ob ich den Darmauszug hinzugesetzt hätte, ehe ich den Pankreasauszug auf seinen eigenen Erepsingehalt hin untersucht hätte!

In noch einem anderen Versuche zeigte ich, daß durch Alkoholzusatz zu einem pankreatischen Auszuge viel mehr Erepsin als Trypsin niedergeschlagen wurde. Herr Dr. Mays sagt, daß er nicht verstehen kann, wie ich die Fermente in Gegenwart von Alkohol quantitativ bestimmen kann, obgleich jedermann dieses sofort verstehen würde, wenn er mit meinen Methoden vertraut wäre (nämlich $1 \mathrm{ccm}$, oder weniger, des Auszuges oder Filtrates werden $9 \mathrm{ccm} \mathrm{Na} \mathrm{CO}_{3}+$ gequollenem Fibrin zugesetzt, oder im Falle des peptonzersetzenden Fermentes werden $0,3 \mathrm{ccm}$, oder weniger, des Filtrates und 9,7 ccm eines 2,5\% igen Wittepeptons $+\mathrm{Na}_{2} \mathrm{CO}_{3}$ zusammengebracht). Die herabdrückende Wirkung des Alkohols ist auf S. 352 meiner Originalabhandlung besprochen worden. 